\title{
IN VITRO $\alpha$-AMYLASE AND A-GLUCOSIDASE INHIBITOR ACTIVITIES OF ALBIZIA PROCERA STEM BARK
}

\author{
ANAND D, SATHISH M*, DHIVYA LS \\ Department of Pharmaceutical Chemistry, College of Pharmacy, Madras Medical College, Chennai, Tamil Nadu, India \\ E-mail: sathishpharmacy14@gmail.com
}

Received: 30 April 2017, Revised and Accepted: 31 May 2018

\section{ABSTRACT}

Objective: This current study was carried out to determine the in vitro $\alpha$-amylase and $\alpha$-glucosidase inhibitory activity of extract and fractions of Albizia procera.

Methods: The $\alpha$-amylase and $\alpha$-glucosidase inhibition assay was carried out at concentrations $50-2000 \mu \mathrm{g} / \mathrm{ml}$ and acarbose used as standard. The absorbance was measured at $540 \mathrm{~nm}$ and recorded by spectrophotometer. Percentage inhibition was calculated for both the assays. Preliminary phytochemical screening was also evaluated using standard procedures.

Results: There was a dose-dependent percentage inhibition of extracts (petroleum ether and ethanol) and fractions (chloroform, ethyl acetate, and n-butanol). The ethanol extract and n-butanol fraction show good inhibitory activity against both $\alpha$-amylase and $\alpha$-glucosidase with the percentage inhibition of $86.20 \%$ and $88.20 \%$ and $83.13 \%$ and $87.10 \%$, respectively. The preliminary phytochemical screening shows that ethanol extract consists of active constituents such as flavonoids and phenolic compounds and tannins.

Conclusion: This finding suggests that the ethanol extract and n-butanol fraction show good inhibitory activity against both $\alpha$-amylase and $\alpha$-glucosidase and show good antidiabetic activity.

Key words: Albizia procera, in vitro antidiabetic, $\alpha$-amylase, $\alpha$-glucosidase.

(C) 2018 The Authors. Published by Innovare Academic Sciences Pvt Ltd. This is an open access article under the CC BY license (http://creativecommons. org/licenses/by/4. 0/) DOI: http://dx.doi.org/10.22159/ajpcr.2018.v11i9.27002

\section{INTRODUCTION}

Diabetes mellitus is a very complicated disease, which can lead to nerve damage and kidney failure, atherosclerosis, blindness, stroke, and heart diseases. There are about 8.3 million diabetics in the United States, of which about 600,000 suffer from type 1 (insulin-dependent) diabetes [1]. The incidence is far higher among some ethnic groups, in which diet play a major role. $50 \%$ of group of native Americans (Pima) over 40 years of age have diabetes. Diabetes is the fifth leading cause of death in the U.S. as well as the leading cause of adult blindness due to diabetic retinopathy and is responsible for $50 \%$ of heart attacks, $75 \%$ of strokes, and $85 \%$ of gangrenous leg amputation due to diabetic peripheral neuropathy $[2,3]$.

Developing countries are the most affected because of expensive and inadequate treatment associated with the synthetic oral hypoglycemic agents. The treatment from medicinal plants exhibits potential agonistic/antagonistic pharmacological agents within themselves due to incorporation of bioactive constituents with variety of pharmacological actions with minimal side effects. These pharmacological principles work together in a dynamic way to produce maximum therapeutic efficacy. There are wide varieties of traditional medicines used for the treatment of diabetes and can combat the threat of diabetic epidemic $[4,5]$.

This plant is used traditionally for the treatment of cancer, convulsions, delirium, and septicemia. The decoction of bark is used traditionally for rheumatism and hemorrhage and is considered useful in treating pregnancy problems, stomach ache, and sinus [6,7]. They were reported to exhibit various pharmacological activities such as CNS activity, cardiotonic activity, lipid-lowering activity, anti-oxidant activity, hepatoprotective activity, and hypoglycemic activity. The leaves of Albizia procera were used for the treatment of variety of wounds and also to suppress skin diseases [8,9]. Seeds are powdered and used in amoebiasis. It cures urinary tract infections including glycosuria, hemorrhoids, fistula, and worm infestation. Fruits of $A$. procera act as astringent and diminish Kapha and Sukra. In India, leaves are used for the treatment of ulcers $[10,11]$.

\section{METHODS}

\section{Collection of plant}

The bark of A. procera was collected from Chennai (near Melur, Madurai), Tamil Nadu, India. The plant material was identified and authenticated by Dr. K.N. Sunil Kumar R.O. and HOD Pharmacognosy, Central Siddha Research Institute, Government of India, Arumbakkam, Chennai-106, authentication code (A17062401P). The bark was dried under shade, segregated, pulverized by a mechanical grinder, and passed through a 40-mesh sieve.

\section{Preparation of plant extracts}

The dried powder of bark was extracted sequentially by hot continuous percolation method by Soxhlet apparatus, using petroleum ether and ethanol as solvent. The extracts were concentrated using a rotary evaporator.

Phytochemical screening of extracts from $A$. procera

The extract was subjected to preliminary qualitative test for the extracts to identify the phytoconstituents present in the bark $[12,13]$.

\section{Fractionation of active extract}

Ethanol extract comprises of flavonoids, tannins, and phenolic compounds, and hence, ethanol extract has been selected for further fractionation using solvents, chloroform, ethyl acetate, and n-butanol. Ethanol extract was filtered through a Buchner funnel fitted with a vacuum pump with a thin layer of activated charcoal and then 
concentrated using a rotary evaporator. The solvent is recovered and the residue is dried. The crude dried ethanol extract was partitioned between equal volumes ( $250 \mathrm{ml}$ each) of distilled water and chloroform. It was shaken for some time and the chloroform layer was separated and concentrated to get a residue, which is considered as chloroform fraction. The aqueous layer which is present was again fractionated by the solvent ethyl acetate. It will be shaken for some time, and ethyl acetate layer was separated and concentrated to get a residue which is considered as ethyl acetate fraction. The aqueous layer was again fractionated by the solvent n-butanol. It was shaken for sometimes and n-butanol layer was separated, concentrated to get a residue, and considered as n-butanol fraction. The aqueous fraction which was remained finally was not used for further study.

\section{In vitro antidiabetic activity}

$\alpha$-amylase assay

$\alpha$-amylase was dissolved in phosphate buffer saline (PBS, $0.02 \mathrm{~mol} / \mathrm{L}$, $\mathrm{pH}$ 6.8) at a concentration of $0.1 \mathrm{mg} / \mathrm{mL}$. Various concentrations of extracts and fractions of $50 \mu \mathrm{g} / \mathrm{ml}-2000 \mu \mathrm{g} / \mathrm{ml}(0.25 \mathrm{~mL})$ were mixed with $\alpha$-amylase solution $(0.25 \mathrm{~mL})$ and incubated at $37^{\circ} \mathrm{C}$ for $5 \mathrm{~min}$. Then, the reaction was initiated by adding $0.5 \mathrm{~mL} 1.0 \%(\mathrm{w} / \mathrm{v})$ starch substrate solution to the incubation medium. After incubation at $37^{\circ} \mathrm{C}$ for $3 \mathrm{~min}$, the reaction was stopped by adding $0.5 \mathrm{~mL}$ DNS reagent ( $1 \%$ dinitrosalicylic acid, $0.05 \% \mathrm{Na}_{2} \mathrm{SO}_{3}$, and $1 \% \mathrm{NaOH}$ solution) to the reaction mixture, and it was boiled at $100^{\circ} \mathrm{C}$ for $5 \mathrm{~min}$. After cooling to room temperature, the absorbance (Abs) was measured at $540 \mathrm{~nm}$ and recorded by a spectrophotometer $[14,15]$. The inhibition percentage was calculated by the following equation:

Inhibition $(\%)=[($ Abs $1-$ Abs2 $) / A b s 1] \times 100$

where Abs1=sample and Abs2 = control

\section{$\alpha$-glucosidase assay}

$\alpha$-glucosidase was dissolved in PBS $(0.02 \mathrm{~mol} / \mathrm{L}, \mathrm{pH} 6.8$ at a concentration of $0.1 \mathrm{mg} / \mathrm{mL}$ [16]. Various concentrations of extracts and fractions of $50 \mu \mathrm{g} / \mathrm{ml}-2000 \mu \mathrm{g} / \mathrm{ml}(0.25 \mathrm{~mL})$ were mixed with $\alpha$-glucosidase solution $(0.25 \mathrm{~mL})$ and incubated at $37^{\circ} \mathrm{C}$ for $5 \mathrm{~min}$. Then, the reaction was initiated by adding $0.5 \mathrm{~mL} 1.0 \%$ (w/v) starch substrate solution to the incubation medium. After incubation at $37^{\circ} \mathrm{C}$ for $3 \mathrm{~min}$, the reaction was stopped by adding $0.5 \mathrm{~mL}$ DNS reagent (1\% dinitrosalicylic acid, $0.05 \% \mathrm{Na}_{2} \mathrm{SO}_{3}$, and $1 \% \mathrm{NaOH}$ solution) to the reaction mixture, and it was boiled at $100^{\circ} \mathrm{C}$ for $5 \mathrm{~min}$. After cooling to room temperature, the Abs was measured at $540 \mathrm{~nm}$ and recorded by a spectrophotometer [17]. The inhibition percentage was calculated by the following equation:

Inhibition $(\%)=[($ Abs1 - Abs2) $/$ Abs1 $] \times 100$

Where Abs1=sample and Abs2 = control.

\section{RESULTS}

From the preliminary phytochemical screening, it was observed that ethanol extract consists of active constituents such as flavonoids and phenolic compounds and tannins. While petroleum ether extract shows the presence of phytosterols, triterpenoids, and fats (Table 1). Hence, ethanol extract was chosen for in vitro antidiabetic study since flavonoids and phenolic compounds play a major role in diabetic research.

In alpha-amylase inhibition assay, as illustrated in Table 2, reveals that ethanol extract has greater alpha amylase inhibition with the percentage inhibition of $86.20 \%$ at $2000 \mu \mathrm{g} / \mathrm{ml}$. The petroleum ether extract shows weak percentage inhibition of $57.11 \%$ at $2000 \mu \mathrm{g} / \mathrm{ml}$.

In alpha-glucosidase inhibition assay, as illustrated in Table 3, it reveals that ethanol extract has greater alpha-glucosidase inhibition with the percentage inhibition of 88.2027 at $2000 \mu \mathrm{g} / \mathrm{ml}$. Petroleum ether extract shows the percentage inhibition of $59.90 \%$ at $2000 \mu \mathrm{g} / \mathrm{ml}$. The ethanol extract shows greater $\alpha$-amylase and $\alpha$-glucosidase inhibition than standard acarbose.
Table 1: Preliminary phytochemical analysis on bark extracts of A. procera

\begin{tabular}{llll}
\hline S.NO & Test & Petroleum ether & Ethanol \\
\hline 1 & Alkaloids & - & - \\
2 & Carbohydrates and glycosides & - & + \\
3 & Phytosterols & + & + \\
4 & Triterpenoids & + & + \\
5 & Flavonoids & - & + \\
6 & Phenolic compounds and tannins & - & + \\
7 & Protein and amino acid & - & - \\
8 & Saponins & - & + \\
9 & Fixed oils and fats & + & - \\
\hline +: Positive, -: Negative. A. procera: Albizia procera
\end{tabular}

Table 2: Effect of extracts on percentage inhibition of $\alpha$-amylase

\begin{tabular}{lll}
\hline Concentration $\mu \mathbf{g} / \mathbf{m l}$ & Petroleum ether extract & Ethanol extract \\
\hline 50 & $4.23729 \pm 0.04$ & $22.8669 \pm 0.04$ \\
100 & $11.0236 \pm 0.06$ & $31.7221 \pm 0.07$ \\
250 & $20.1413 \pm 0.03$ & $50.655 \pm 0.06$ \\
500 & $33.3333 \pm 0.05$ & $66.8622 \pm 0.04$ \\
1000 & $54.251 \pm 0.02$ & $81.3839 \pm 0.03$ \\
2000 & $57.1157 \pm 0.04$ & $86.2027 \pm 0.05$ \\
\hline
\end{tabular}

Each value in the table was obtained by calculating the average of three experiments and data are presented as mean \pm SEM

Table 3: Effect of extracts on percentage inhibition of $\alpha$-glucosidase

\begin{tabular}{lll}
\hline Concentration $\mu \mathrm{g} / \mathbf{m l}$ & Petroleum Ether extract & Ethanol extract \\
\hline 50 & $5.11029 \pm 0.09$ & $27.8069 \pm 0.14$ \\
100 & $11.8036 \pm 0.12$ & $38.7021 \pm 0.09$ \\
250 & $21.1413 \pm 0.08$ & $56.655 \pm 0.17$ \\
500 & $34.3333 \pm 0.11$ & $69.8622 \pm 0.08$ \\
1000 & $53.201 \pm 0.06$ & $83.3039 \pm 0.09$ \\
2000 & $59.9057 \pm 0.05$ & $88.2027 \pm 0.07$ \\
\hline
\end{tabular}

Each value in the table was obtained by calculating the average of three experiments, and data are presented as Mean \pm SEM

As described in Table 4, the fractions, chloroform, ethyl acetate, and n-butanol also have greater alpha-amylase inhibition than standard acarbose. n-butanol fraction has greater alpha-amylase inhibition than chloroform and ethyl acetate fraction. The percentage inhibition of n-butanol fraction against alpha-amylase was found to be $83.104 \%$. Interestingly, it was observed that n-butanol fraction has greater alphaamylase inhibition than standard acarbose with $79.37 \%$ inhibition. The results of extracts and fractions against alpha-amylase are also depicted in Figs. 1 and 2.

As described in Table 5, the fractions, chloroform, ethyl acetate, and n-butanol also have greater alpha-glucosidase inhibition than standard acarbose. The n-butanol fraction has greater alpha glucosidase inhibition than chloroform and ethyl acetate fraction. The percentage inhibition of n-butanol fraction against alpha-glucosidase is found to be $87.100 \%$. The $n$-butanol fraction has greater alpha-glucosidase inhibition than standard acarbose with $74.37 \%$ inhibition. The results of extracts and fractions against alpha-amylase are also depicted in Figs. 3 and 4.

\section{DISCUSSION}

The antioxidants (tannins, flavonoids, Vitamins $\mathrm{C}$ and $\mathrm{E}$, etc.) have the capacity to prevent the destruction of $\beta$-cells by inhibiting the peroxidation chain reaction, by which they may provide protection against the development of diabetes [18]. The mechanism of tannins as antidiabetic activity is by Mitogen-Activated Protein Kinase activation and GLUT-4 translocation $[19,20]$. The protective effects of flavonoids 
Table 4: Effect of fractions of $A$. procera on percentage inhibition of $\alpha$-amylase

\begin{tabular}{lllc}
\hline Concentration $\mu \mathbf{g} / \mathbf{m l}$ & Chloroform fraction & Ethyl acetate fraction & n-butanol fraction \\
\hline 50 & $1.31004 \pm 0.04$ & $0.87719 \pm 0.07$ & $14.41860 \pm 0.04$ \\
100 & $28.7066 \pm 0.06$ & $23.1293 \pm 0.05$ & $24.27983 \pm 0.07$ \\
250 & $43.7811 \pm 0.03$ & $48.2838 \pm 0.03$ & $46.51162 \pm 0.05$ \\
500 & $64.5768 \pm 0.09$ & $73.2861 \pm 0.06$ & $66.6061 \pm 0.09$ \\
1000 & $79.5104 \pm 0.07$ & $84.5417 \pm 0.02$ & $81.6410 \pm 0.03$ \\
2000 & $81.6467 \pm 0.02$ & $80.822 \pm 0.04$ & $83.1304 \pm 0.02$ \\
\hline
\end{tabular}

Each value in the table was obtained by calculating the average of three experiments and data are presented as Mean \pm SEM. A. procera: Albizia procera

Table 5: Effect of fractions of $A$. procera on percentage inhibition of $\alpha$ - glucosidase

\begin{tabular}{|c|c|c|c|c|}
\hline Concentration $(\mu \mathrm{g} / \mathrm{ml}$ level) & Chloroform fraction & Ethyl acetate fraction & n-butanol fraction & Acarbose Standard \\
\hline 50 & $2.30004 \pm 0.04$ & $1.90719 \pm 0.05$ & $16.40860 \pm 0.05$ & $5.04202 \pm 0.06$ \\
\hline 100 & $29.7066 \pm 0.06$ & $25.1093 \pm 0.07$ & $27.27983 \pm 0.08$ & $21.7993 \pm 0.08$ \\
\hline 250 & $51.7811 \pm 0.06$ & $50.2838 \pm 0.11$ & $49.51162 \pm 0.12$ & $34.1108 \pm 0.07$ \\
\hline 500 & $68.5768 \pm 0.08$ & $76.2861 \pm 0.15$ & $70.6061 \pm 0.10$ & $42.9293 \pm 0.05$ \\
\hline 1000 & $80.5014 \pm 0.07$ & $82.0017 \pm 0.17$ & $81.6010 \pm 0.05$ & $53.4979 \pm 0.03$ \\
\hline 2000 & $83.6067 \pm 0.04$ & $82.902 \pm 0.06$ & $87.1004 \pm 0.04$ & $74.3764 \pm 0.04$ \\
\hline
\end{tabular}

Each value in the table was obtained by calculating the average of three experiments and data are presented as Mean \pm SEM

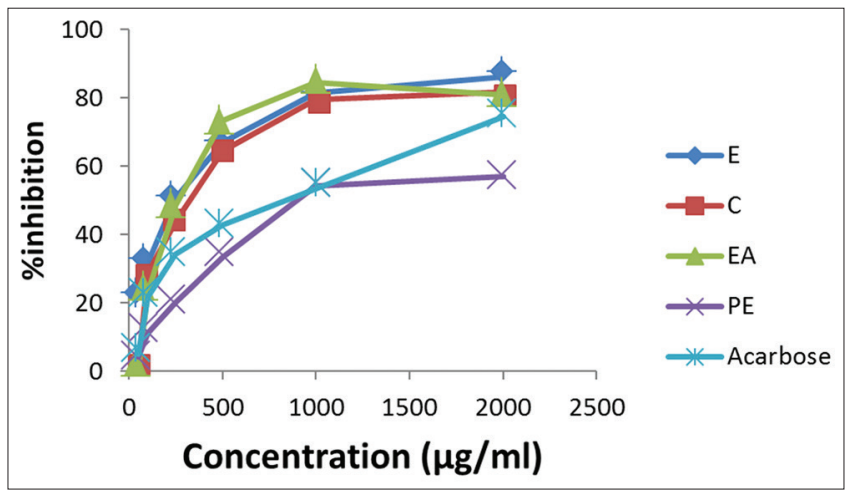

Fig. 1: $\alpha$-amylase inhibition assay of extract and fractions from Albizia procera. E - Ethanolextract, C - Chloroform extract, EA Ethyl acetate fraction, PE - Petroleum ether fraction, Acarbose (Standard

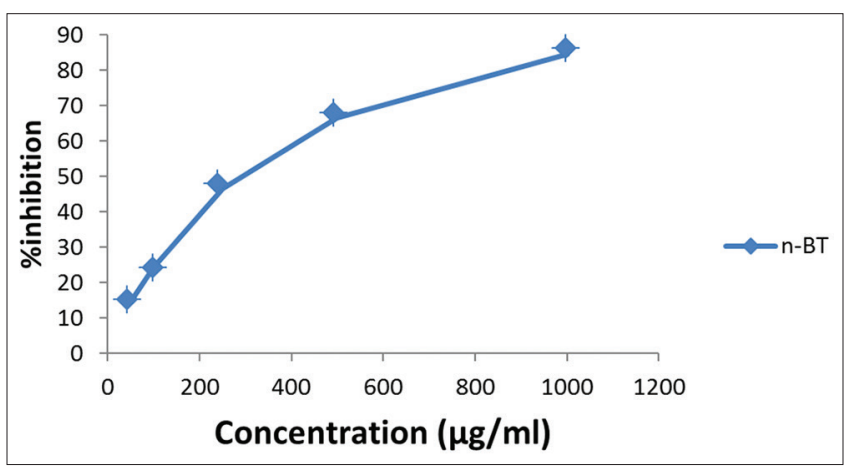

Fig. 2: $\alpha$-amylase inhibition assay of n-butanol (n-BT) fraction of Albizia procera

against diabetes are by (a) acting as free radical scavengers and (b) activating antioxidant enzymes which may be suppressed by the oxidative stress induced by hypoglycemia [21]. Moreover, fibers of plants may also interfere in the absorption of carbohydrates and thus may have an effect on blood glucose [22].

The extracts and fractions of $A$. procera showed significant $\alpha$-amylase inhibitory activity. $\alpha$-amylases catalyze the hydrolysis of $\alpha-1$, 4-glucosidic linkage of starch to initiate starch digestion and promote

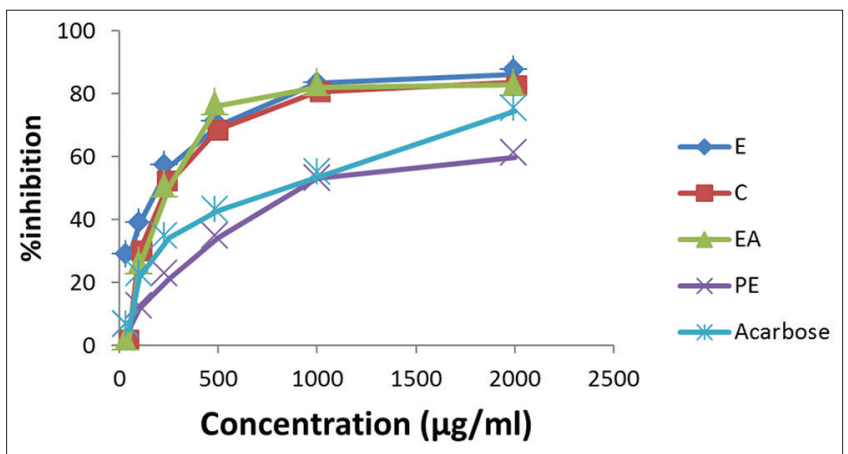

Fig. 3: $\alpha$-glucosidase inhibition assay of extract and fractions from Albizia procera. E - Ethanol extract, C - Chloroform extract, EA Ethyl acetate fraction, PE - Petroleum ether fraction, Acarbose (Standard)

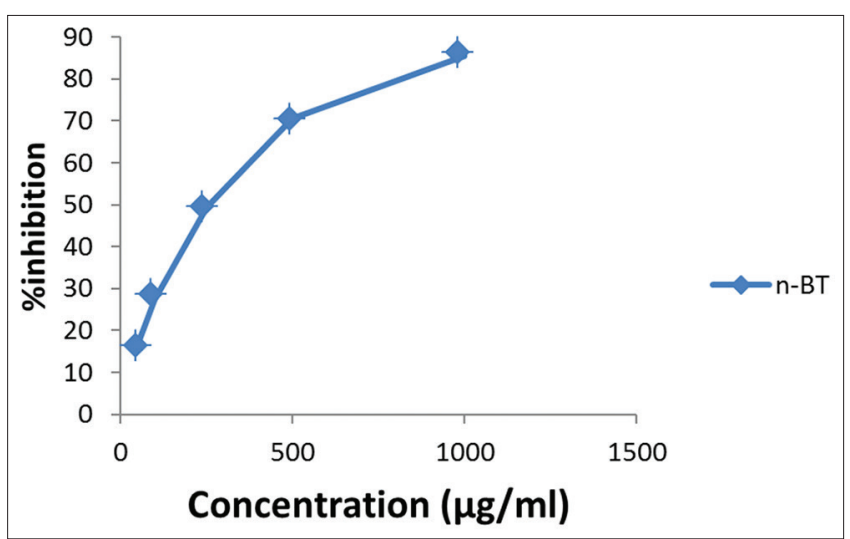

Fig. 4: $\alpha$-glucosidase inhibition assay of n-butanol (n-BT) fraction from Albizia procera

glucose absorption. $\alpha$-amylase inhibitors were considered to be effective in diabetes control [23]. The extracts and fractions of A. procera also show significant $\alpha$-glucosidase inhibitory activity. $\alpha$-glucosidase constitutes a family of enzymes hydrolase, located in the brush-border surface membrane of small intestinal cells, and it is the key enzyme by which the final step of digestion is catalyzed [24]. Hence, glucosidase inhibitors can stop the liberation of D-glucose from complex dietary carbohydrates and can delay the glucose absorption which in turn 
reduce blood glucose level and decrease hyperglycemia $[25,26]$. In this present study, in vitro $\alpha$-amylase and $\alpha$-glucosidase inhibitor activity of extracts and fractions of $A$. procera stem bark were evaluated. The retardation and delay of carbohydrate absorption with a plant-based $\alpha$-amylase and $\alpha$-glucosidase inhibitor offer a prospective therapeutic approach for the management of type 2 diabetes mellitus.

\section{CONCLUSION}

From above these observations, it is concluded that the ethanol extract and $\mathrm{n}$-butanol fraction of $A$. procera have good in vitro antidiabetic activity by evaluating against alpha-amylase and alpha-glucosidase inhibition assay. The flavonoids and phenolic compounds present in ethanol extract may be responsible for the in vitro antidiabetic activity. However, the active principles responsible for inhibitory action of $\alpha$-amylase and $\alpha$-glucosidase need to be identified and characterized for the development of indigenous botanical resources for novel hypoglycemic drug development.

\section{ACKNOWLEDGMENTS}

The authors are thankful to the Department of Pharmaceutical Chemistry, College of Pharmacy, Madras Medical College, providing the facilities to carry out the research.

\section{CONFLICTS OF INTEREST}

All authors have none to declare.

\section{AUTHOR'S CONTRIBUTIONS}

All authors contributed equally to this work. D. Anand and Dr. M. Sathish, carried out the extraction, fractionation, and preliminary phytochemical screening of extracts. D. Anand, Dr. M.Sathish, and L.S Dhivya equally contributed the in vitro $\alpha$-amylase and $\alpha$-glucosidase inhibitory activities of stem bark of $A$. procera. Dr. M.Sathish wrote the main paper, and all the authors discuss the results and implications and commented on the manuscript at all stages. All authors contributed extensively to the work presented in paper.

\section{REFERENCES}

1. Brain J, Welch MD, Ivana Z. Diabetic ketoacidosis in Type 2 diabetes. Clin Diabetes 2004;22:198-2000.

2. Lutt R, Minkowski O. Discovery of the pancreatic origin of diabetes. Diabetologia 1989;32:399-401

3. Rother KI. Diabetes treatment-bridging the divide. N Engl J Med 2007;356:1499-501.

4. Eisenberg DM, Kessler RC, Foster C, Norlock FE, Calkins DR, Delbanco TL, et al. Unconventional medicine in the united states. Prevalence, costs, and patterns of use. N Engl J Med 1993;328:246-52.

5. MacLennan AH, Wilson DH, Taylor AW. Prevalence and cost of alternative medicine in australia. Lancet 1996;347:569-73.

6. Parotta JA, Roshetko JM. Albizia procera-White Siris for Reforestation and Agroforestry. FACTNet FACT Sheet No. 97-01. Morrilton, USA:
Winrock International; 1997. Available from: http://www.winrock.org/ forestry/factpub/factsh/ALBPRO.htm.

7. Sivakrishnan S, Kottaimuthu A, Kavitha J. GC-MS analysis of ethanolic extract of aerial parts of Albizia procera (Roxb.) Benth. Int J Pharm Pharm Sci 2013;5:702-4.

8. Rajanarayana K, Reddy MS, Chaluvadi MR, Krishna DR. Bioflavonoids classification, pharmacological, biochemical effects and therapeutic potential. Indian J Pharmacol 2001;33:2-16.

9. Chopda MZ, Mahajan RT. Wound healing plants of Jalgaon district of Maharashtra state, India. Ethnobotanical Leaf 2009;13:1-32.

10. Sitaram B, Chunekar KC. Bhavaprakasa of Bhavamisra, Edn Reprint. Vol. 1. New Delhi: Jayyed Press; 2012. p. 354.

11. Anon. The Useful Plants of India. New Delhi, India: Publications \& Information Directorate, CSIR; 1986.

12. Harborne JB. Phytochemical Methods. $11^{\text {th }}$ ed. New York: In Chapman \&, Hall; 1984. p. 4-5.

13. Kokate CK. Practical Pharmacognosy. $3^{\text {rd }}$ ed. New Delhi: Vallabh Prakashanre; 1994. p. 107-9.

14. Elya B, Handayani R, Sauriasari R, Azizahwati, Hasyyati US, Permana It. Antidiabetic activity and phytochemical screening of extracts from Indonesian plants by inhibition of alpha amylase, alpha glucosidase and dipeptidyl peptidase IV. Pak J Biol Sci 2015;18:279-84.

15. Maeda K, Kakabayashi S, Matsubara H. Complete amino acid sequence of an alpha-amylase inhibitor in wheat kernel (0.19-inhibitor). Biochim Biophys Acta 1985;828:213-21.

16. Matsui T, Yoshimoto C, Osajima K, Oki T, Osajima Y. In vitro survey of $\alpha$-glucosidase inhibitory food components. Bios Biot Biochem 1996;60:2019-22.

17. Pujiyanto S, Lestari Y, Suwanto A, Budiarti S, Darusman LK. Alphaglucosidase inhibitor activity and characterization of endophytic actinomycetes isolated from some Indonesian diabetic medicinal plants. Int J Pharm Pharm Sci 2012;4:327-33.

18. Aslan M, Orhan N, Orhan DD, Ergun F. Hypoglycemic activity and antioxidant potential of some medicinal plants traditionally used in Turkey for diabetes. J Ethnopharmacol 2010;128:384

19. Kunyanga $\mathrm{CN}$, Imungi JK, Okoth M, Momanyi C, Biesalski HK, Vadivel V. Antioxidant and antidiabetic properties of condensed tannins in acetonic extract of selected raw and processed indigenous food ingredients from Kenya. J Food Sci 2011;76:560-7.

20. Watkins SV. Nutrition Research Advances. New York: Nova Science Publishers; 2007. p. 1-223.

21. Marella S. Flavonoids-the most potent poly-phenols as antidiabetic agents: An overview. Modern Approach Drug Design 2017;1:1-5.

22. Perez RM, Zavala GM, Perez SG, Perez CG. Antidiabetic effect of compounds isolated from plants. Phytomedicine 1998;5:55.

23. Marles RJ, Farnsworth NR. Antidiabetic plants and their active constituents. Phytomedicine 1995;2:137.

24. Ojewole JA. Laboratory evaluation of the hypoglycemic effect of Anacardium occidentale Linn (Anacardiaceae) stem-bark extracts in rats. Methods Fin Exp Clin Pharmacol 2003;25:199.

25. Bahmani M, Golshahi H, Saki K, Rafieian-Kopaei M, Delfan B, Mohammadi T. Medicinal plants and secondary metabolites for diabetes mellitus control. Asian Pac J Trop Disease 2014;4:5687.

26. Van de Laar FA, Lucassen PL, Akkermans RP, Van de Lisdonk EH, Rutten GE, Van Weel C. Alpha-glucosidase inhibitors for Type 2 diabetes mellitus. Cochrane Database Syst Rev 2005;18:1-5. 